\title{
Effects of lifestyle modification after breast cancer treatment: a systematic review protocol
}

\author{
Maicon Falavigna ${ }^{1,2,3}$, Karine Margarites Lima ${ }^{1,3}$, Juliana Giacomazzi ${ }^{4}$, Diego d'Avila Paskulinn ${ }^{3,4}$, \\ Luciano Serpa Hammes ${ }^{1}$, Rodrigo Antonini Ribeiro ${ }^{1,3}$ and Daniela Dornelles Rosa ${ }^{1,5^{*}}$
}

\begin{abstract}
Background: There is no consensus in the literature regarding the effectiveness of lifestyle modification interventions, including recommendations about specific diet or exercise program for patients with breast cancer. Diet interventions and regular physical activity may reduce the risk of breast cancer and its recurrence. The primary aim of our study is to evaluate the effects of different lifestyle modification interventions (diet and physical activity) in the survival of patients with stages I to III breast cancer after treatment.
\end{abstract}

Methods/design: This review will be conducted according to the Cochrane Handbook for Systematic Reviews of Intervention and will be reported following the PRISMA statement recommendations. CENTRAL, MEDLINE and EMBASE databases will be searched for peer-reviewed literature. Randomized controlled trials of diet, exercise, or both, compared with usual care, after treatment of breast cancer stage I to III will be included in the systematic review. Two authors will independently screen titles and abstracts of studies for potential eligibility. Data will be combined using random-effect meta-analysis models with restricted maximum-likelihood as variance estimator, and will be presented as relative risk or standardized mean difference with $95 \% \mathrm{Cl}$. The quality of evidence will be assessed using the Grading of Recommendations Assessment, Development and Evaluation (GRADE) framework and summary of findings tables will be presented for patient important outcomes.

Discussion: Our study may improve the current understanding of the role that lifestyle-modifiable factors can play in saving or prolonging the lives of women who have been treated for breast cancer, and also on modifying their quality of life.

Systematic review registration: The review has been registered with PROSPERO (registration number CRD42014008743).

Keywords: Breast cancer, Lifestyle interventions, Exercise, Diet, Physical activity, Systematic review, Adjuvant chemotherapy

\section{Background}

High body mass index (BMI) is well established as a risk factor for the development of breast cancer, especially for post-menopausal women [1,2]. More than half of women diagnosed with breast cancer experience an increase in body weight associated with chemotherapy and treatment-related menopause [3]. Additionally, there is evidence that overweight or obese women and women

\footnotetext{
*Correspondence: daniela.rosa@hmv.org.br

'Institute for Education and Research, Hospital Moinhos de Vento, Rua

Ramiro Barcellos 910, Porto Alegre 90035-001, Brazil

${ }^{5}$ Oncology Unit, Hospital Moinhos de Vento, Hospital Moinhos de Vento, Rua Ramiro Barcellos 910, Porto Alegre 90035-001, Brazil

Full list of author information is available at the end of the article
}

with weight gain after diagnosis have an increased risk of disease recurrence and death compared to eutrophic women [4-8]. Women with a high body mass index have double the risk of five-year breast cancer recurrence and a $60 \%$ increased risk of death over 10 years in comparison to women with a normal BMI [6].

Dietary energy restriction reduces body weight, promoting a positive effect on psychological wellbeing in obese women and breast cancer survivors [9-11]. Weight loss interventions that reduce the dietary intake of fat to between 18 and $25 \%$ of total calories can also evoke a significant reduction in serum estrogen levels in pre- and post-menopausal women [12]. A diet rich in vegetables and 
fruits may decrease the risk of breast cancer and a diet high in total fat may increase the risk [13]. However, evidence of an association between a diet high in vegetables and fruit and low in total fat, and prevention of cancer progression has been conflicting in epidemiological studies [8,14-21].

Regular physical activity can help to control body weight and is known to reduce the risk of breast cancer [22-25]. Additional studies also suggest that it can halve the risk of death in breast cancer patients [26,27]. Regular physical activity can also have a positive effect on psychological health status and quality of life in breast cancer survivors that could enhance immune function through the normalization of stress hormone levels [28-30].

There is no consensus in the literature regarding the effectiveness of lifestyle modification interventions, including recommendations about a specific diet or exercise program for patients with breast cancer. The results of observational studies evaluating lifestyle modification and breast cancer recurrence have been mixed. In addition, the randomized clinical trials that have been published are inconclusive [31,32] and there are no recent systematic reviews assessing this topic. Therefore, the primary aim of our study is to evaluate the effects of different lifestyle modification interventions (diet and physical activity) in the survival and disease-free survival of patients with stages I to III breast cancer after treatment.

\section{Methods/design}

We will conduct this review according to the Cochrane Handbook for Systematic Reviews of Intervention [33] and we will report data following the PRISMA statement recommendations [34].We will assess the quality of evidence for each outcome according to Grading of Recommendations Assessment, Development and Evaluation (GRADE) framework [35,36]. The review has been registered with PROSPERO (registration number: CRD42014008743).

\section{Inclusion criteria}

The type of studies included will be randomized controlled trials of diet, exercise, or both, compared to usual care, after treatment of breast cancer stage I to III. The participants to be included will be women with invasive breast cancer, stage I to III, who were treated with curative intent in the previous five years, with no evidence of disease recurrence. The types of interventions considered will be as follows: (1) dietary advice delivered through group meetings, by telephone calls, or by mail correspondence; (2) individualized dietary counseling; (3) prescription of a specific diet, such as a calorie-restricted diet; (4) any type of exercise counseling that encouraged women to engage in regular recreational exercises, such as walking, jogging or sports; and (5) structured or individualized exercise programs or interventions in which women participated in supervised exercise sessions.

\section{Types of outcomes}

The primary outcomes of the systematic review are overall survival and disease-free survival (five years post treatment and at the study maximum follow-up period for both outcomes).

We will also evaluate the following secondary outcomes: (1) diet and exercise related modifiable risk factors (weight, BMI, waist-hip ratio and body fat); (2) mediators and other metabolic factors potentially associated with breast cancer (adiponectin, leptin, IGF-1, IGFBP1, IGFBP2, insulin, C-peptide, HOMA-IR, estradiol, testosterone and SHBG); (3) quality of life; and (4) adverse events (such as exercise-induced injuries or side effects of very low-calorie diets).

\section{Search strategy and sources}

The following electronic databases will be searched for peer-reviewed literature: Cochrane Database of Systematic Reviews, Cochrane Central Register of Controlled Trials (CENTRAL), MEDLINE, and EMBASE. The search strategy was developed based on search strategies from published filters and systematic reviews [37-39], and is detailed in Additional file 1.

In addition, we will perform an electronic search for ongoing studies at ClinicalTrials.gov and hand searches of reference lists of included articles and of the proceedings of the following major conferences: American Society of Clinical Oncology (2010 to 2014), San Antonio Breast Cancer Symposium (2010 to 2014), European Society of Medical Oncology (2010 to 2014), Society for Integrative Oncology (2010 to 2014), American Association for Cancer Research (AACR) (2010 to 2014), and World Cancer Research Fund International (2010 to 2014).

\section{Data collection and analysis Study selection}

Two authors will independently screen titles and abstracts of studies for potential eligibility. Full texts of potentially eligible studies will be retrieved and two authors will independently apply inclusion criteria to identify relevant studies to be included in the review. Disagreement will be resolved through discussion; if necessary, a third reviewer will be involved. We will provide a table with characteristics of included studies, and another table of excluded studies with reasons for their exclusion, in the final review.

\section{Data extraction and management}

Two reviewers will independently extract data using a standardized form. The following data will be abstracted: (1) characteristics of trial participants (age, ethnicity, BMI, weight, body fat, waist-hip ratio, breast cancer stage, treatment, and breast cancer biological subtype); (2) type of intervention (such as type of diet or exercise 
program); (3) outcome measures and their definition according to individual studies; and (4) methodological quality of individual studies, according to the Cochrane Handbook for Systematic Reviews [33].

Disagreement will be resolved through discussion. When quantitative data is not reported, approximate values will be estimate from the figures or calculated from proportions.

\section{Quality assessment}

The risk of bias of all eligible studies will be assessed independently by two reviewers using the Cochrane Collaboration's Risk of Bias tool [33]. Disagreement will be resolved through discussion. Overall quality of evidence will be assessed using GRADE by a GRADE working group member and will checked by a second reviewer $[35,36]$.

\section{Data synthesis and presentation}

Data will be combined using random-effect meta-analysis models, with restricted maximum-likelihood (REML) variance estimator and presented as relative risks (RR) or standardized mean difference (SMD) with 95\% confidence intervals (CI). All analyses will be performed using the R software, version 3.0.2 (R: A Language and Environment for Statistical Computing, Vienna, Austria); packages 'meta' version 3.0-1 (meta: Meta-Analysis with R. R package version) and 'metafor' version 1.9-1 (Conducting meta-analyses in $\mathrm{R}$ with the metafor package) [40,41]. GRADE summary of findings tables will be presented for the primary outcomes $[42,43]$.

\section{Heterogeneity}

We will assess statistical heterogeneity in each metaanalysis using the $\mathrm{I}^{2}$ statistics. We will regard heterogeneity as substantial if the $\mathrm{I}^{2}$ is greater than $50 \%$. Heterogeneity will be explored through pre-specified subgroup and sensitivity analysis as presented below.

\section{Publication bias}

If there are 10 or more studies in the meta-analysis we will investigate publication bias using funnel plots and Egger`s test [44]. If asymmetry is suggested by a visual assessment, we will perform exploratory analyses to investigate and adjust it (trim and fill analysis) [45].

\section{Missing data}

For included studies, we will note levels of attrition. We will explore the impact of including studies with high levels of missing data in the overall assessment of treatment effect by using sensitivity analysis.

For all outcomes, we will carry out analyses, as far as possible, on an intention-to-treat basis, in that we will attempt to include all participants randomized to each group in the analyses, and all participants will be analyzed in the group to which they were allocated, regardless of whether or not they received the allocated intervention. The denominator for each outcome in each trial will be the number randomized minus the number of participants whose outcomes are known to be missing.

\section{Sensitivity analysis}

In order to identify potential sources of heterogeneity, we will perform the following subgroup analysis: (1) type of intervention (diet, exercise, or both); (2) breast cancer treatment (adjuvant versus neoadjuvant); (3) tumor stage (according to AJCC) [46]; (4) subtypes of breast cancer according to immunohistochemistry (positivity for HR and/or HER2); (5) Mean follow-up period ( $\geq 24$ months) and (6) risk of bias of included studies). Additionally, meta-regression will be performed according to the mean follow-up period of the included studies.

\section{Discussion}

The results of this study may improve our understanding of the role that lifestyle-modifiable factors can play in saving or prolonging the lives of women who have been treated for breast cancer, and also on modifying their quality of life. Additionally, this study will provide evidence that may be used for the development of recommendations in guidelines of breast cancer treatment.

\section{Additional file}

Additional file 1: Search strategy for electronic databases. Search strategy developed for CENTRAL, MEDLINE (OVID) and EMBASE (OVID).

\section{Abbreviations}

AJCC: American Joint Committee on Cancer; BMI: Body mass index; HER2: Human epidermal growth factor receptor 2; HOMA-IR: Homeostasis model assessment-estimated insulin resistance; HR: Hormone receptor; IGF1: Insulin-like growth factor 1; IGFBP1: Insulin-like growth factor-binding protein 1; IGFBP2: Insulin-like growth factor-binding protein 2; SHBG: Sex hormone-binding globulin

\section{Competing interests}

The authors declare that they have no competing interests.

\section{Authors' contributions}

DDR conceived the study and gave final approval for the protocol. MF selected methods for use, developed the search strategy and drafted the protocol. KML collaborated in the design of the study, reviewed and edited the protocol. JG collaborated in the design of the study, reviewed and edited the protocol. DDP collaborated in the design of the study, reviewed and edited the protocol. LSH collaborated in the design of the study, reviewed and edited the protocol. RAR collaborated in the design of the study, reviewed and edited the protocol. All authors read and approved the final manuscript.

\section{Acknowledgements}

The publication of this protocol was supported by funding from Hospital Moinhos de Vento, Porto Alegre, Brazil. Hospital Moinhos de Vento is a private non-profit institution. There were no further funding sources. 


\section{Author details}

1 Institute for Education and Research, Hospital Moinhos de Vento, Rua Ramiro Barcellos 910, Porto Alegre 90035-001, Brazil. Department of Clinical Epidemiology and Biostatistics, McMaster University, 1280 Main Street West, Hamilton L8S 4L8, Canada. ${ }^{3}$ Postgraduate Program in Epidemiology, Universidade Federal do Rio Grande do Sul, Rua Ramiro Barcellos 2400, Porto Alegre 90035-003, Brazil. ${ }^{4}$ Molecular Biology Laboratory, Santa Casa de Misericórdia de Porto Alegre, Rua Professor Annes Dias 295, Porto Alegre 90035-001, Brazil. ${ }^{5}$ Oncology Unit, Hospital Moinhos de Vento, Hospital Moinhos de Vento, Rua Ramiro Barcellos 910, Porto Alegre 90035-001, Brazil.

\section{Received: 25 March 2014 Accepted: 17 June 2014}

Published: 5 July 2014

\section{References}

1. Cheraghi Z, Poorolajal J, Hashem T, Esmailnasab N, Doosti Irani A: Effect of body mass index on breast cancer during premenopausal and postmenopausal periods: a meta-analysis. PLOS One 2012, 7:e51446.

2. Munsell MF, Sprague BL, Berry DA, Chisholm G, Trentham-Dietz A: Body mass index and breast cancer risk according to postmenopausal estrogen-progestin use and hormone receptor status. Epidemiol Rev 2014, 36:114-136.

3. Holmes $\mathrm{MD}$, Kroenke $\mathrm{CH}$ : Beyond treatment: lifestyle choices after breast cancer to enhance quality of life and survival. Womens Health Issues 2004, 14:11-13.

4. Camoriano JK, Loprinzi CL, Ingle JN, Therneau TM, Krook JE, Veeder MH: Weight change in women treated with adjuvant therapy or observed following mastectomy for node-positive breast cancer. Am J Clin Oncol 1990, 8:1327-1334

5. Chlebowski RT, Aiello E, McTiernan A: Weight loss in breast cancer patient management. Am J Clin Oncol 2002, 20:1128-1143.

6. Goodwin PJ, Boyd NF: Body size and breast cancer prognosis: a critical review of the evidence. Breast Cancer Res Treat 1990, 16:205-214.

7. Schapira DV, Kumar NB, Lyman GH, Cox CE: Obesity and body fat distribution and breast cancer prognosis. Cancer 1991, 67:523-528.

8. Zumoff B, Gorzynski JG, Katz JL, Weiner H, Levin J, Holland J, Fukushima DK: Nonobesity at the time of mastectomy is highly predictive of 10-year disease-free survival in women with breast cancer. Anticancer Res 1982, 2:59-62.

9. Djuric Z, DiLaura NM, Jenkins I, Darga L, Jen CK, Mood D, Bradley E, Hryniuk WM: Combining weight-loss counseling with the weight watchers plan for obese breast cancer survivors. Obes Res 2002, 10:657-665.

10. Jen KL, Djuric Z, DiLaura NM, Buison A, Redd JN, Maranci V, Hryniuk WM: Improvement of metabolism among obese breast cancer survivors in differing weight loss regimens. Obes Res 2004, 12:306-312

11. Kaukua J, Pekkarinen T, Sane T, Mustajoki P: Health-related quality of life in obese outpatients losing weight with very-low-energy diet and behaviour modification: a 2-y follow-up study. Int J Obes Relat Metab Disord 2003, 27:1072-1080.

12. Wu AH, Pike MC, Stram DO: Meta-analysis: dietary fat intake, serum estrogen levels, and the risk of breast cancer. J Natl Cancer Inst 1999, 91:529-534

13. Wiseman M: The second world cancer research fund/American Institute for Cancer Research expert report. Food, nutrition, physical activity, and the prevention of cancer: a global perspective. Proc Nutr Soc 2008, 67:253-256

14. Beasley JM, Newcomb PA, Trentham-Dietz A, Hampton JM, Bersch AJ, Passarelli MN, Holick CN, Titus-Ernstoff L, Egan KM, Holmes MD, Willett WC: Post-diagnosis dietary factors and survival after invasive breast cancer. Breast Cancer Res Treat 2011, 128:229-236.

15. Holm LE, Nordevang E, Hjalmar ML, Lidbrink E, Callmer E, Nilsson B: Treatment failure and dietary habits in women with breast cancer. J Natl Cancer Inst 1993, 85:32-36.

16. Ingram D: Diet and subsequent survival in women with breast cancer Br J Cancer 1994, 69:592-595

17. Jain M, Miller $A B$, To T: Premorbid diet and the prognosis of women with breast cancer. J Natl Cancer Inst 1994, 86:1390-1397.

18. Kroenke $\mathrm{CH}$, Fung $\mathrm{TT}$, Hu FB, Holmes MD: Dietary patterns and survival after breast cancer diagnosis. Am J Clin Oncol 2005, 23:9295-9303.

19. Pierce JP, Stefanick ML, Flatt SW, Natarajan L, Sternfeld B, Madlensky L, Al-Delaimy WK, Thomson CA, Kealey S, Hajek R, Parker BA, Newman VA,
Caan B, Rock CL: Greater survival after breast cancer in physically active women with high vegetable-fruit intake regardless of obesity. Am J Clin Oncol 2007, 25:2345-2351.

20. Rock CL, Demark-Wahnefried W: Nutrition and survival after the diagnosis of breast cancer: a review of the evidence. Am J Clin Oncol 2002, 20:3302-3316.

21. Zhang S, Folsom AR, Sellers TA, Kushi LH, Potter JD: Better breast cance survival for postmenopausal women who are less overweight and eat less fat. Cancer 1995, 76:275-283.

22. Gao Y, Huang YB, Liu XO, Chen C, Dai HJ, Song FJ, Wang J, Chen KX Wang YG: Tea consumption, alcohol drinking and physical activity associations with breast cancer risk among chinese females: a systematic review and meta-analysis. Asian Pac J Cancer Prev 2013, 14:7543-7550.

23. Moradi T, Adami HO, Bergstrom R, Gridley G, Wolk A, Gerhardsson M, Dosemeci M, Nyren O: Occupational physical activity and risk for breast cancer in a nationwide cohort study in Sweden. Cancer Causes Contro 1999, 10:423-430.

24. Wu Y, Zhang D, Kang S: Physical activity and risk of breast cancer: a meta-analysis of prospective studies. Breast Cancer Res Treat 2013, 137:869-882.

25. Rockhill B, Willett WC, Hunter DJ, Manson JE, Hankinson SE, Colditz GA A prospective study of recreational physical activity and breast cancer risk. Arch Intern Med 1999, 159:2290-2296.

26. Ibrahim EM, Al-Homaidh A: Physical activity and survival after breast cancer diagnosis: meta-analysis of published studies. Med Oncol 2011, 28:753-765

27. Holmes MD, Chen WY, Feskanich D, Kroenke CH, Colditz GA: Physical activity and survival after breast cancer diagnosis. JAMA 2005, 293:2479-2486.

28. Blanchard CM, Courneya KS, Rodgers WM, Murnaghan DM: Determinants of exercise intention and behavior in survivors of breast and prostate cancer: an application of the theory of planned behavior. Cancer Nurs 2002, 25:88-95.

29. Campbell A, Mutrie N, White F, McGuire F, Kearney N: A pilot study of a supervised group exercise programme as a rehabilitation treatment for women with breast cancer receiving adjuvant treatment. Eur J Oncol Nurs 2005, 9:56-63.

30. Segar ML, Katch VL, Roth RS, Garcia AW, Portner TI, Glickman SG, Haslanger S, Wilkins EG: The effect of aerobic exercise on self-esteem and depressive and anxiety symptoms among breast cancer survivors. Oncol Nurs Forum 1998, 25:107-113.

31. Pierce JP, Natarajan L, Caan BJ, Parker BA, Greenberg ER, Flatt SW, Rock CL, Kealey S, Al-Delaimy WK, Bardwell WA, Carlson RW, Emond JA, Faerber S, Gold EB, Hajek RA, Hollenbach K, Jones LA, Karanja N, Madlensky L, Marshall J, Newman VA, Ritenbaugh C, Thomson CA, Wasserman L, Stefanick ML: Influence of a diet very high in vegetables, fruit, and fiber and low in fat on prognosis following treatment for breast cancer: the Women's Healthy Eating and Living (WHEL) randomized trial. JAMA 2007, 298:289-298.

32. Blackburn GL, Wang KA: Dietary fat reduction and breast cancer outcome: results from the Women's Intervention Nutrition Study (WINS). Am J Clin Nutr 2007, 86:s878-s881.

33. Higgins JPT, Green S: Cochrane Handbook for Systematic Reviews of Interventions Version 5.1.0 [updated March 2011]. The Cochrane Collaboration; 2011. www.cochrane-handbook.org.

34. Liberati A, Altman DG, Tetzlaff J, Mulrow C, Gotzsche PC, loannidis JP, Clarke M, Devereaux PJ, Kleijnen J, Moher D: The PRISMA statement for reporting systematic reviews and meta-analyses of studies that evaluate healthcare interventions: explanation and elaboration. BMJ 2009, 339:b2700.

35. Balshem $H$, Helfand M, Schunemann HJ, Oxman AD, Kunz R, Brozek J, Vist GE, Falck-Ytter Y, Meerpohl J, Norris S, Guyatt GH: GRADE guidelines: 3. Rating the quality of evidence. J Clin Epidemiol 2011, 64:401-406.

36. Guyatt $G H$, Oxman AD, Vist GE, Kunz R, Falck-Ytter $Y$, Alonso-Coello P, Schunemann HJ, Group GW: GRADE: an emerging consensus on rating quality of evidence and strength of recommendations. BMJ 2008, 336:924-926.

37. Scottish Intercollegiate Guidelines Network: Search Filters. In [http:// www.sign.ac.uk/methodology/filters.html]

38. Cochrane Breast Cancer Group: Cochrane Breast Cancer Group's module. In [http://onlinelibrary.wiley.com/o/cochrane/clabout/articles/BREASTCA/ frame.html]. 
39. Orozco LJ, Buchleitner AM, Gimenez-Perez G, Roque IFM, Richter B, Mauricio D: Exercise or exercise and diet for preventing type 2 diabetes mellitus. Cochrane Database Syst Rev 2008, CD003054.

40. Schwarzer G: Package 'meta': Meta-Analysis with R. In Book Package 'meta'? Meta-Analysis with R. City: The R Foundation for Statistical Computing; 2013. http://CRAN.R-project.org/package $=$ meta.

41. Viechtbauer $\mathrm{W}$ : Conducting meta-analyses in $\mathrm{R}$ with the metafor package. J Stat Software 2010, 36:1-48.

42. Guyatt GH, Oxman AD, Santesso N, Helfand M, Vist G, Kunz R, Brozek J, Norris S, Meerpohl J, Djulbegovic B, Alonso-Coello P, Post PN, Busse JW, Glasziou P, Christensen R, Schünemann HJ: GRADE guidelines: 12. Preparing summary of findings tables-binary outcomes. J Clin Epidemiol 2013, 66:158-172.

43. Guyatt GH, Thorlund K, Oxman AD, Walter SD, Patrick D, Furukawa TA, Johnston BC, Karanicolas P, Akl EA, Vist G, Kunz R, Brozek J, Kupper LL, Martin SL, Meerpohl JJ, Alonso-Coello P, Christensen R, Schunemann HJ: GRADE guidelines: 13 . Preparing summary of findings tables and evidence profiles-continuous outcomes. J Clin Epidemiol 2013, 66:173-183.

44. Egger M, Davey Smith G, Schneider M, Minder C: Bias in meta-analysis detected by a simple, graphical test. BMJ 1997, 315:629-634.

45. Duval S, Tweedie R: Trim and fill: a simple funnel-plot-based method of testing and adjusting for publication bias in meta-analysis. Biometrics 2000, 56:455-463.

46. Edge S, Byrd DR, Compton CC, Fritz AG, Greene FL, Trotti A (Eds): AJCC Cancer Staging Manual. 7th edition. New York: Springer-Verlag; 2010:347.

doi:10.1186/2046-4053-3-72

Cite this article as: Falavigna et al.: Effects of lifestyle modification after breast cancer treatment: a systematic review protocol. Systematic Reviews 2014 3:72.

\section{Submit your next manuscript to BioMed Central and take full advantage of:}

- Convenient online submission

- Thorough peer review

- No space constraints or color figure charges

- Immediate publication on acceptance

- Inclusion in PubMed, CAS, Scopus and Google Scholar

- Research which is freely available for redistribution 